\title{
Assessment of Model Predictive Control Performance
}

\section{Criteria}

\author{
Rafael Lopes Duarte-Barros ${ }^{1 *}$ and Song Won Park ${ }^{2}$ \\ 1. Emerson Process Management, Rio de Janeiro 20.090-003, Brazil \\ 2. Department of Chemical Engineering, University of São Paulo, São Paulo 05424-970, Brazil
}

\begin{abstract}
The current highly competitive environment has driven industries to operate with increasingly restricted profit margins. Thus, it is imperative to optimize production processes. Faced with this scenario, multivariable predictive control of processes has been presented as a powerful alternative to achieve these goals. Moreover, the rationale for implementation of advanced control and subsequent analysis of its post-match performance also focus on the benefits that this tool brings to the plant. It is therefore essential to establish a methodology for analysis, based on clear and measurable criteria. Currently, there are different methodologies available in the market to assist with such analysis. These tools can have a quantitative or qualitative focus. The aim of this study is to evaluate three of the best current main performance assessment technologies: Minimum Variance Control-Harris Index; Statistical Process Control ( $\mathrm{Cp}$ and $\mathrm{Cpk}$ ); and the Qin and Yu Index. These indexes were studied for an alumina plant controlled by three MPC (model predictive control) algorithms (GPC (generalized predictive control), RMPCT (robust multivariable predictive control technology) and ESSMPC (extended state space model predictive controller)) with different results.
\end{abstract}

Key words: Predictive controller performance, minimum variance, capability, MPC, GPC, ESSMPC (extended state space model predictive controller).

\section{Introduction}

MPC (model predictive control) is defined as the family of controllers for which there is a direct use of an explicit and separately identifiable model. The model provides predictions of the process response in targeted or constrained CVs (control variables) to future changes in the manipulative variables (MVs, regulatory controllers) and to measured and predicted process disturbances (DVs) [1]. In practice, MPC is characterized by its ability to handle constraints in both manipulated and controlled variables. MPC techniques provide the only methodology to handle constraints in a systematic way during the design and implementation of the controller. Moreover, in its most general form, MPC is not restricted in terms of the model, the objective function and/or constraint functionality. Thus, an explicit mathematical model of

*Corresponding author: Rafael Lopes Duarte-Barrors, M.Sc., research field: chemical engineering and control. E-mail: faelop@yahoo.com.br. a process can be used directly to control a process closer to its optimal or desired conditions. These are the primary reasons for the success of these techniques in numerous applications in chemical process industries. While several extension projects have gradually increased the plant size and complexity, the resulting regularity, variability reduction and challenges for throughput increase are met via MPC implementation. Moreover, pushing the capacity limits requires a control tool such as MPC, which will better handle the varying set of active constraints.

\subsection{GPC (Generalized Predictive Control) Controller}

The GPC (generalized predictive control) algorithm is a long-range predictive controller using the input-output internal model from Eq. (1) to have knowledge of the process in question [2].

$$
\begin{gathered}
A\left(q^{-1}\right) y(t)=B\left(q^{-1}\right) u(t-1)+ \\
C\left(q^{-1}\right) \frac{\xi(t)\left[1-(1-\beta) q^{-1}\right]}{\Delta}
\end{gathered}
$$


The scope of the GPC control law is to keep the future output of the process as near as possible to the reference trajectory so that the integral of the quadratic error is minimized.

\subsection{RMPCT (Robust Multivariable Predictive Control Technology) Controller}

RMPCT is a range control algorithm with a finite horizon that implements smoother control actions to achieve its objectives. Instead of specific trajectories, the controller works in ranges, bringing more degrees of freedom for the resolution of the optimization problem. Thus, in this controller's algorithm, optimization with restrictions is achieved, dividing the controller into two parts: the first part is a steady state quadratic programming algorithm, which is used to solve the restricted optimization problem. This solution, in the form of targets, is then used by the linear control law to generate a set of movements on the manipulated variables so that the system can be dynamically handled. The $\mathrm{H}_{2}$ control problem can be described as [3]:

$$
\min _{\Delta u, v} \frac{1}{2}\|W(S \Delta u-v)\|_{2}^{2}
$$

Subjected to

$$
\begin{gathered}
y_{L} \leq v \leq y_{H} \\
u_{L} \leq u \leq u_{H} \\
\Delta u_{L} \leq \Delta u \leq \Delta u_{H}
\end{gathered}
$$

where, $S$ is the system matrix, such that the outputs prediction is given by $\mathrm{y}=S \Delta \mathrm{u}$, with $u$ being the process inputs. Actually the concept involves a maximum singular value, Frobenius norm and $\mathrm{H}_{2}$ norm. The vector 2-norm of control moves and Frobenius norm of the controller are related in the minimization task.

\subsection{ESSMPC Controller}

ESSMPC stands for extended state space model predictive controller [4]. In said controller, there are two time horizons: one for future outputs predictions (prediction horizon) and another horizon for the past (identification horizon). The horizon for the past defines a sequence of past inputs and outputs, and this sequence is used to reconstruct the present state of the process by applying a subspace-based algorithm [5]. Due to the observability, there is a minimum identification horizon that is necessary to reconstruct the present plant state:

$$
\left\{\begin{array}{c}
x_{k+1}=A x_{k}+B u_{k} \\
y_{k}=D x_{k}
\end{array}\right.
$$

The control law is given by

$$
\begin{aligned}
\mathfrak{I}_{k}=\sum_{i=1}^{L}\left(y_{k+i}\right. & \left.-r_{k+i}^{r e f}\right) q_{k+i}\left(y_{k+i}-r_{k+i}^{r e f}\right) \\
& +\Delta u_{k+i-1} r_{k+i-1} \Delta u_{k+i-1} \\
& +\left(u_{k+i-1} p_{k+i-1} u_{k+i-1}\right)
\end{aligned}
$$

The optimization problem is given by

$$
\min \mathfrak{I}_{k}
$$

\section{Performance Evaluation Techniques}

\subsection{Minimum Variance-Harris Index}

The utilization of a minimum variance controller as the reference to evaluate single loop controllers was proposed in [6]. This reference is estimated based on closed loop data. After this work, it was proposed the use of a performance index, which is the ratio between the best achievable variance and the current variance of a certain output. In the expression that defines the controller outputs, there is one more term, whose variance is different than zero, as in the next equation [7]:

$$
y(t+k)=\phi D(t+k)+\hat{y}(t)
$$

Defining

$$
E\left[\left(\hat{y}(t)^{2}\right)\right]=\sigma_{\text {soc }}^{2}
$$

Then,

$$
\sigma_{y}^{2}=\sigma_{s o c}^{2}+\sigma_{m v c}^{2}
$$

where, $s o c$ is the term for suboptimal control and $m v c$ is the term for the minimum variance control. Then, the CPI (controller performance index) is calculated by the following Eq. (9): 


$$
C P I=\frac{\sigma_{m v c}^{2}}{\sigma_{s o c}^{2}+\sigma_{m v c}^{2}} \in[0,1]
$$

It was proposed a method for the minimum variance controller of MIMO (multiple input-multiple output) systems using the FCOR (filter and correlation) algorithm, which calculates the performance index based on the optimum covariance $\left(\Sigma_{m v}\right)$ and the real process variance matrix $\left(\Sigma_{y}\right)$ [8]. In this case, the performance index is calculated by

$$
\eta=\frac{\operatorname{tr} \Sigma_{m v}}{\operatorname{tr} \Sigma_{Y}}
$$

\subsection{Statistical Process Control}

The usual statistical process control index is the Capability Index, defined on the tolerance interval centered by the process mean. The process capability usually is assumed to be six times the calculated standard deviation, so the capability index is given by the Eq. (11):

$$
C_{p}=\frac{U S L-L S L}{6 \widehat{\sigma}}
$$

where,

$L S L$ : lower specification limit

USL: upper specification limit

$\sigma$ : standard deviation

\subsection{Qin and Yu Index}

A data-based covariance benchmark for control performance monitoring was proposed in [9]. It is defined as a period of reference data of a user-specified benchmark, generally a period of "golden" operation data from the process with satisfactory control performance, usually after a satisfactory controller tuning or updating. Considering the benchmark period to be 1 and the monitored period 2 , the direction along which there is the largest variance ratio of the monitored period versus the benchmark period is attained as:

$$
p=\operatorname{argmax} \frac{p^{T} \operatorname{cov}\left(y_{2}\right) p}{p^{T} \operatorname{cov}\left(y_{1}\right) p}
$$

where, $\operatorname{cov}\left(y_{1}\right)$ and $\operatorname{cov}\left(y_{2}\right)$ denote the covariance matrices of the benchmark period 1 and the monitored period 2 , respectively.

To assess the overall control performance of a process in the monitored period versus the benchmark period, the authors defined the performance index as follows:

$$
I_{v}=\frac{\left|\operatorname{cov}\left(y_{I I}\right)\right|}{\left|\operatorname{cov}\left(y_{I}\right)\right|}=\prod_{i=1}^{q} \lambda_{i}
$$

\section{Case Study: Alumina Plant}

\subsection{Process Description}

An alumina refinery (Fig. 1), is designed to extract alumina from bauxite [10]. Four tons of bauxite yield approximately two tons of alumina, which yield approximately one ton of aluminum. The digesters mix the heated spent liquor and bauxite slurry to reach a target digestion temperature. They then maintain that temperature for a period of time sufficient to dissolve the alumina from the bauxite and to reduce the silica dissolved by the desilication reaction to a tolerable level. Table 1 summarizes the controlled, manipulated and disturbance variables relevant for the present application. The DBO (digeston blow-off) ratio is the digester blow-off ratio, the main parameter to determine digestion yield.

\subsection{Plant Performance before MPC Implementation}

Fig. 2 shows an example of the CVs' and MVs' behavior before MPC implementation. Table 2 summarizes the plant performances of this traditional control of the plant.

To calculate the performance indexes for the real process data (Table 2), a set of 7,000 samples was extracted from the plant historian system operation. After that, the models for RMPCT were identified with an independent set of data, and the plant was simulated with the existing conventional control system in MATLAB (matrix laboratory)/simulink using the inputs exactly as they were in the plant, aiming to obtain similar output responses. The response of the 


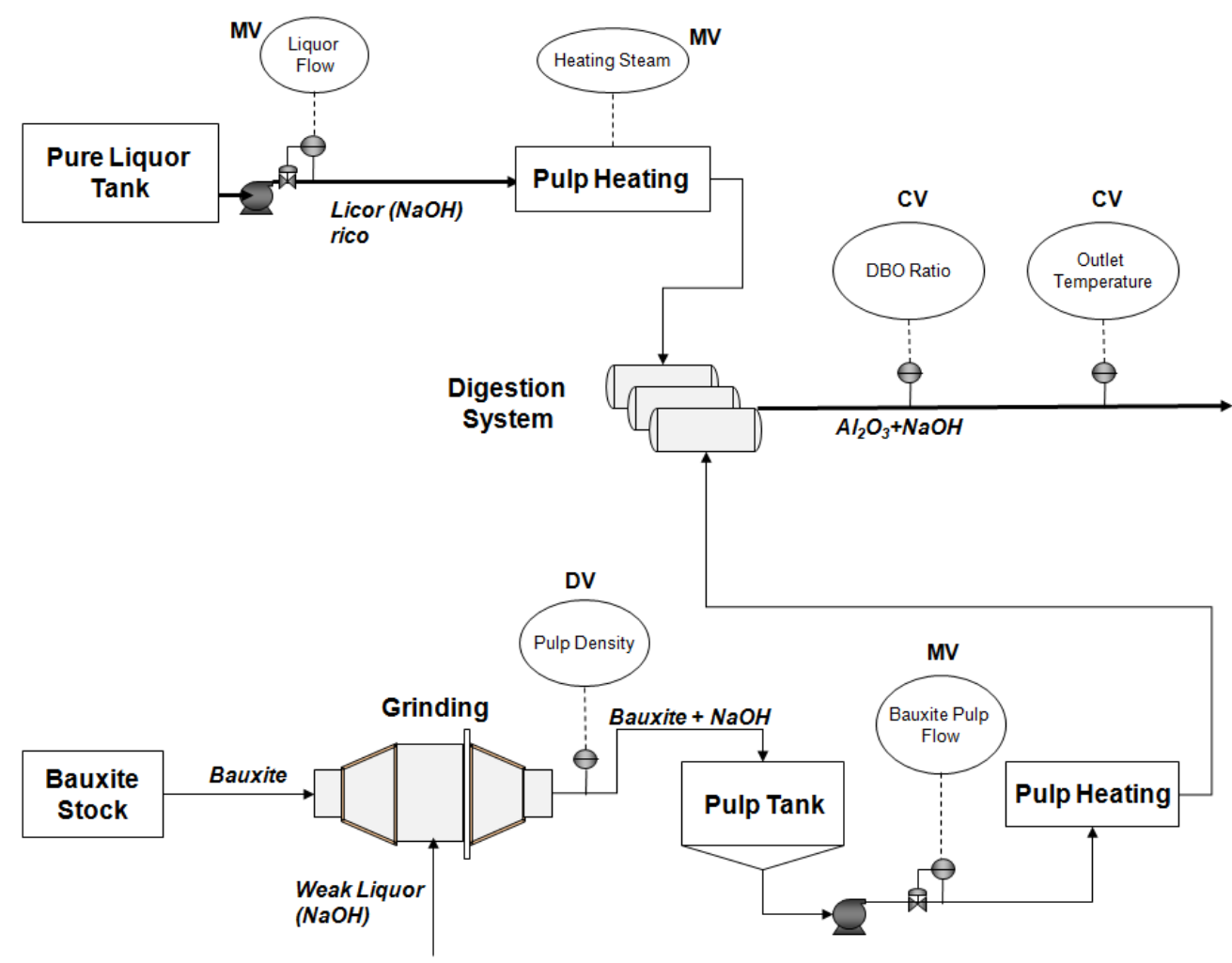

Fig. 1 An alumina refinery.

Table 1 Variables of the alumina refinery.

\begin{tabular}{lll}
\hline Manipulated variables & Controlled ariables & Disturbance variables \\
\hline Bauxite pulp flow $\left(\mathrm{MV}_{1}\right)$ & DBO ratio $\left(\mathrm{CV}_{1}\right)$ & Bauxite pulp density $\left(\mathrm{DV}_{1}\right)$ \\
Liquor flow $\left(\mathrm{MV}_{2}\right)$ & Residence time $\left(\mathrm{CV}_{2}\right)$ & \\
Heating steam flow $\left(\mathrm{MV}_{3}\right)$ & Digestion outlet temperature $\left(\mathrm{CV}_{3}\right)$ & \\
\hline
\end{tabular}

main controlled variable (DBO ratio) is shown in Fig. 3 with this simulated data for the conventional control system. Other control outputs have best fits between real and simulated data than the Fig. 3. New indexes values were calculated for simulated outputs, and the results are summarized in Table 3 for comparison with Table 2. The indexes and the controlled variable responses are similar to those of the real plant. This certified the authors to test MPC controllers with the simulated plant, just inserting the same disturbance as in the real plant. Table 4 summarizes the models identified for RMPCT.

\subsection{Plant Models for GPC and ESSMPC (Extended State Space Model Predictive Controller)}

Plant models are obtained by plant data identification and can be summarized in Tables 5 and 6 .

\subsection{Results}

Although the implementation and simulation of all of the GPC, RMPCT and ESSMPC control systems were conducted, for the sake of conciseness, only the outputs of the ESSMPC controller are shown in Fig. 4, with the main parameters Identification Horizon $=30$, Control Horizon $=30$, Weights (for all) $\mathrm{MVs}=1$, and Weights (for all) $\mathrm{CVs}=1$. One can compare Fig. 6 with Fig. 2.

After the initial results, the controller weights for the main output $\mathrm{DBO}$ ratio, that is, $\mathrm{CV}_{1}$, were changed for each one of the 3 controller algorithms to simulate the controller's and indexes' reactions to these changes. The weight changes for $\mathrm{CV}_{1}$ are 1, 2, 3, 4, 5, 


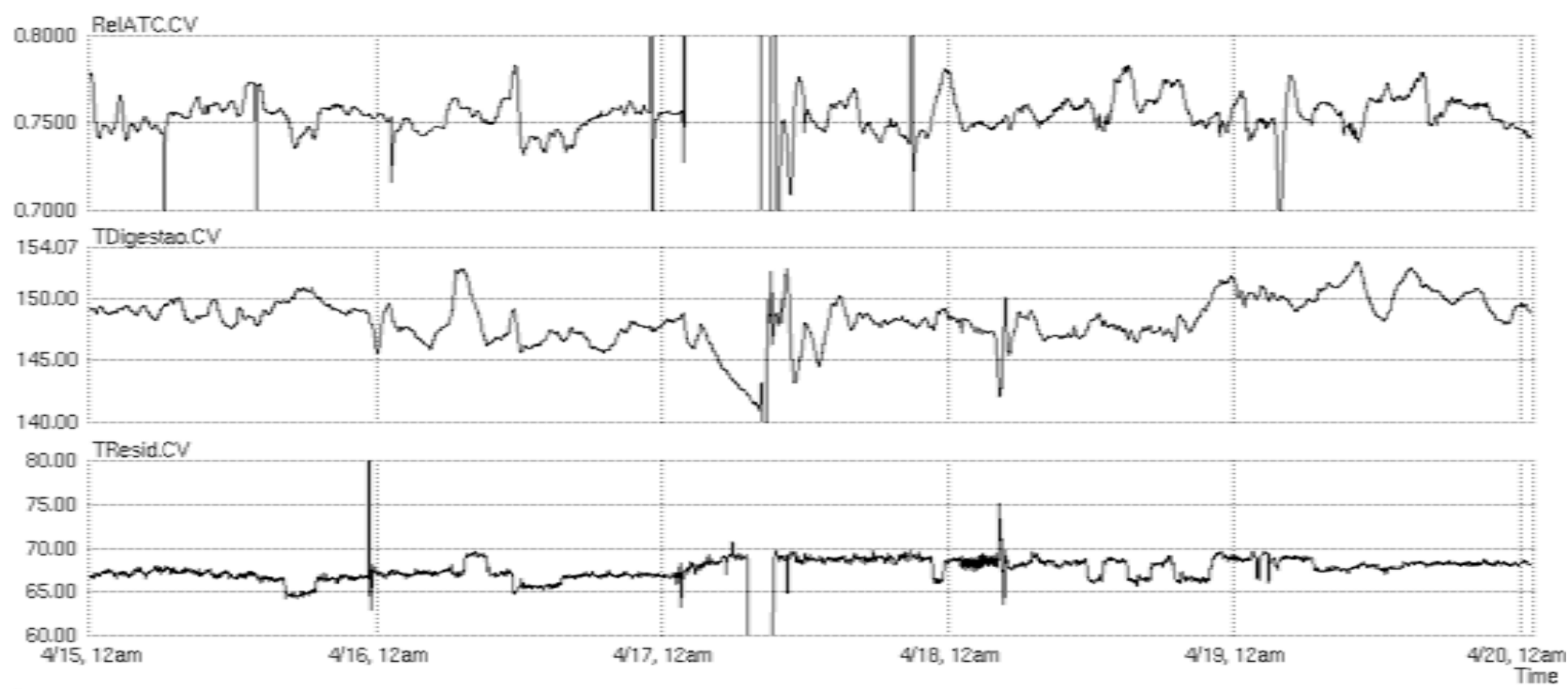

(a)

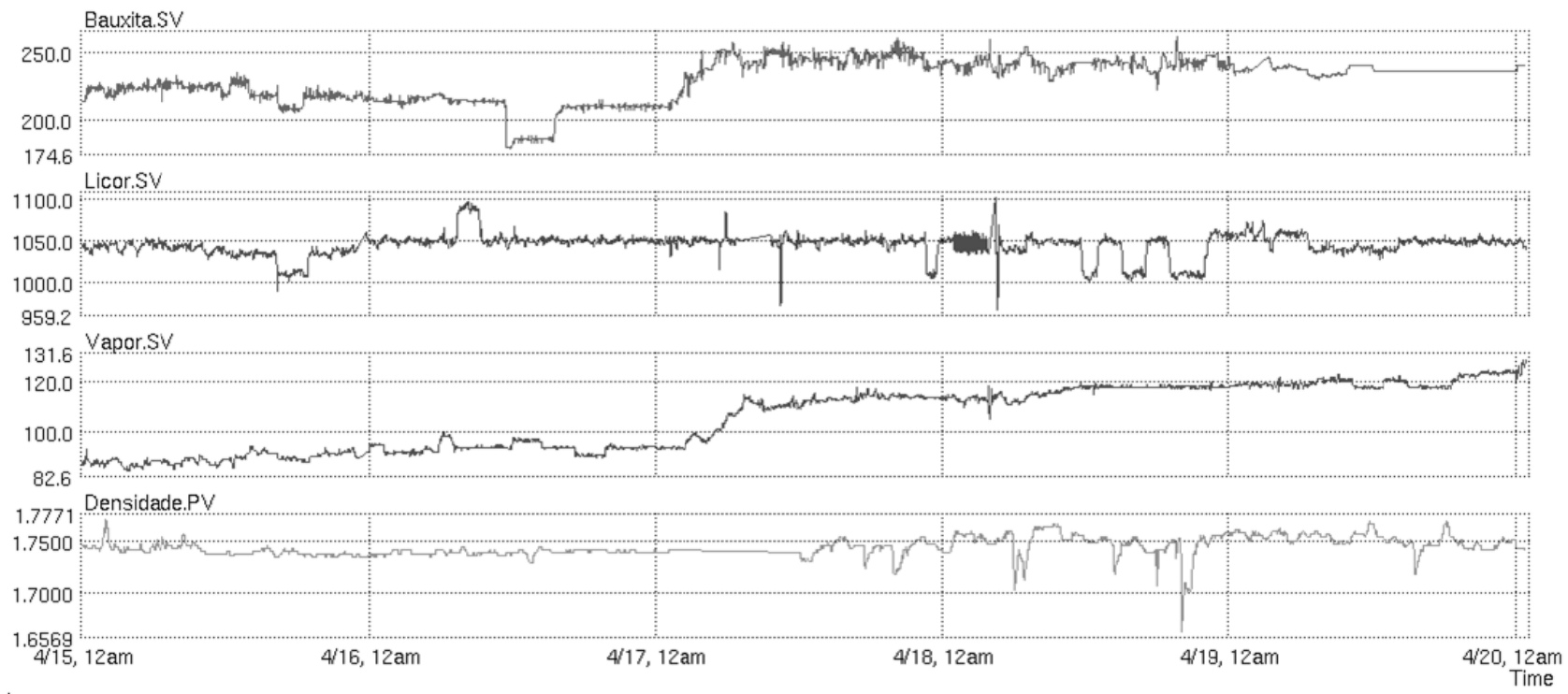

(b)

Fig. 2 (a) CVs before MPC implementation (DBO ratio, temperature, residence time), (b) MVs and DVs before MPC implementation (bauxite flow, liquor flow, steam flow, density).

Table 2 Plant performance indexes before MPC-based on real plant data of traditional control.

\begin{tabular}{llllll}
\hline & Std. dev & Average & LSL/USL & Cp/Cpk & Harris index \\
\hline DBO ratio & 0.0056 & 0.754 & $0.75 / 0.76$ & $0.521 / 0.412$ & 0.385 \\
Residence time & 2.42 & 67.01 & $60 / 70$ & $0.689 / 0.413$ & 0.620 \\
Digestion temperature & 2.41 & 148.28 & $144-148$ & $0.277 / 0.038$ & 0.028 \\
\hline
\end{tabular}

Table 3 Plant performance indexes before MPC-based on simulated plant data of traditional control.

\begin{tabular}{llllll}
\hline & Std. dev & Average & LSL/USL & Cp/Cpk & Harris index \\
\hline DBO ratio & 0.0047 & 0.753 & $0.75 / 0.76$ & $0.354 / 0.212$ & 0.367 \\
Residence time & 2.55 & 66.87 & $60 / 70$ & $0.653 / 0.410$ & 0.598 \\
Digestion temperature & 2.49 & 147.89 & $144-148$ & $0.267 / 0.014$ & 0.020 \\
\hline
\end{tabular}




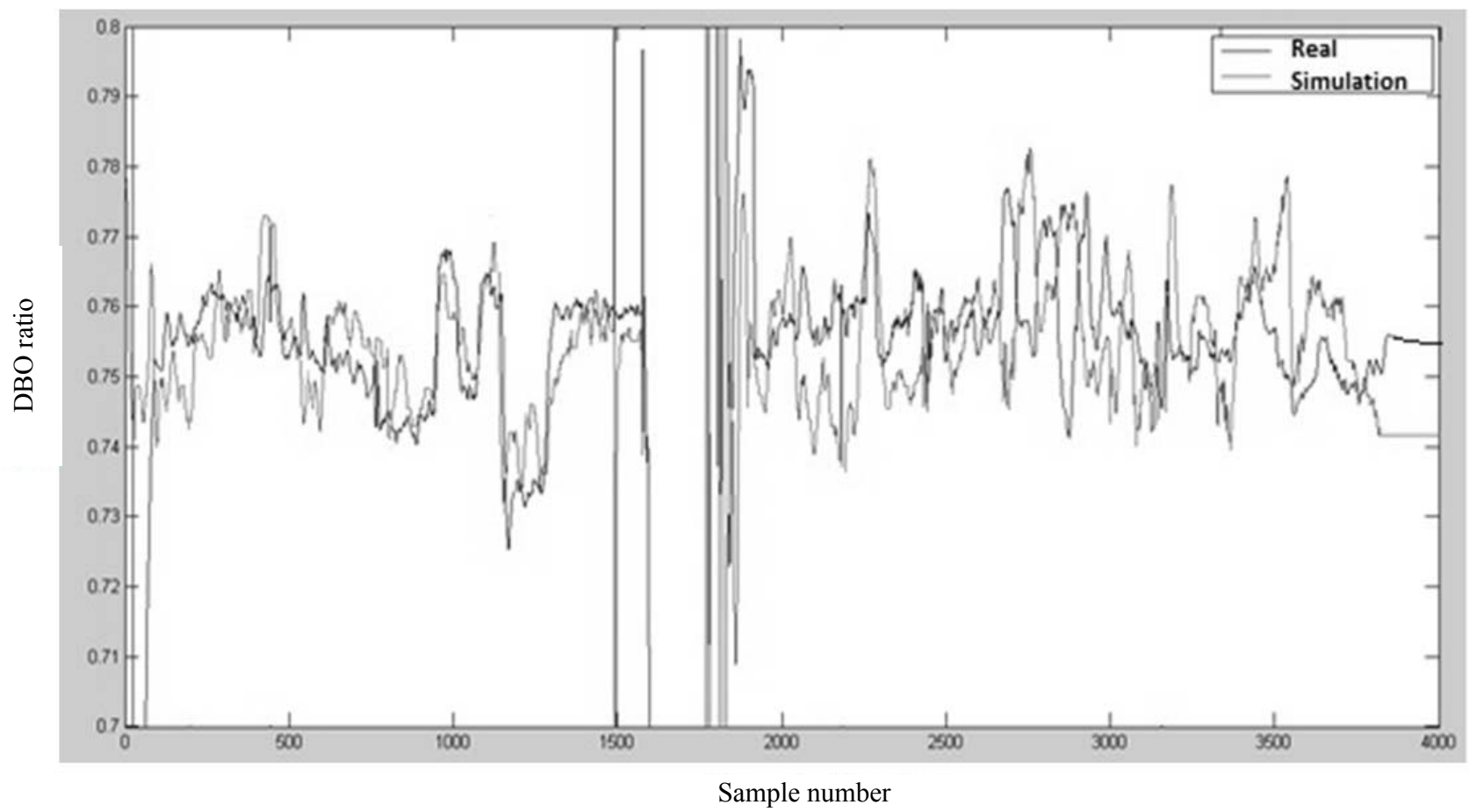

Fig. 3 DBO real $\times$ DBO simulated.

Table 4 Models for RMPCT controllers.

\begin{tabular}{clll}
\hline & $\begin{array}{l}\text { DBO ratio } \\
\mathrm{CV}_{1}\end{array}$ & $\begin{array}{l}\text { Residence time ratio } \\
\mathrm{CV}_{2}\end{array}$ & $\begin{array}{l}\text { Outlet digestion temperature } \\
\mathrm{CV}_{3}\end{array}$ \\
\hline $\mathrm{MV}_{1}$ bauxite & $-0.011 \frac{s+0.1}{535 s^{2}+44 s+1} e^{-42}$ & $-\frac{0.0424(s+1)}{5 s+1} e^{-6}$ & $-0.957 \frac{s+0.036}{125 s^{2}+49 s+1} e^{-25}$ \\
$\mathrm{MV}_{2}$ liquor & $-0.000062 \frac{s-0.05}{19 s^{2}+27 s+1} e^{-36}$ & $-0.0424 \frac{s+1}{5 s+1} e^{-6}$ & $-0.127 \frac{s+0.02}{210 s^{2}+41 s+1} e^{-19}$ \\
$\mathrm{MV}_{3}$ steam & & & $0.202 \frac{s-0.15}{18 s^{2}+6 s+1} e^{-1}$ \\
$\mathrm{DV}_{1}$ density & $1.035 \frac{s+0.43}{25 s^{2}+17 s+1} e^{-42}$ & & \\
\hline
\end{tabular}

Table 5 ARMAX models for GPC controllers.

\begin{tabular}{cll}
\hline $\begin{array}{l}\text { DBO ratio } \\
\mathrm{CV}_{1}\end{array}$ & $\begin{array}{l}\text { Residence time ratio } \\
\mathrm{CV}_{2}\end{array}$ & $\begin{array}{l}\text { Outlet digestion temperature } \\
\mathrm{CV}\end{array}$ \\
\hline $\mathrm{A}(\mathrm{q})=1-1.092 \mathrm{q}^{-1}-0.1157 \mathrm{q}^{-2}-\mathrm{A}(\mathrm{q})=1-\mathrm{q}^{-1}$ & $\mathrm{~A}(\mathrm{q})=1-1.092 \mathrm{q}^{-1}-0.1157 \mathrm{q}^{-2}-$ \\
$0.2135 \mathrm{q}^{-3}+0.4306 \mathrm{q}^{-4}$ & & $0.2135 \mathrm{q}^{-3}+0.4306 \mathrm{q}^{-4}$ \\
$\mathrm{C}(\mathrm{q})=1-1.061 \mathrm{q}^{-1}-0.2912 \mathrm{q}^{-2}+\mathrm{C}(\mathrm{q})=1-0.9995 \mathrm{q}^{-1}$ & $\mathrm{C}(\mathrm{q})=1-1.061 \mathrm{q}^{-1}-0.2912 \mathrm{q}^{-2}+$ \\
$0.2134 \mathrm{q}^{-3}+0.189 \mathrm{q}^{-4}$ & $0.2134 \mathrm{q}^{-3}+0.189 \mathrm{q}^{-4}$ \\
$\mathrm{~B}_{1}(\mathrm{q})=0.0001614 \mathrm{q}^{-42}-0.0003299$ & $\mathrm{~B}_{1}(\mathrm{q})=0.0001614 \mathrm{q}^{-42}-0.0003299$ \\
$\mathrm{MV}_{1}$ bauxite & $\mathrm{B}_{1}(\mathrm{q})=-0.04297+0.04297 \mathrm{q}^{-1}$ & $\mathrm{q}^{-43}+0.0001153 \mathrm{q}^{-44}$ \\
$\mathrm{q}^{-43}+0.0001153 \mathrm{q}^{-44}$ & $\mathrm{~B}_{2}(\mathrm{q})=3.599 .10^{-6} \mathrm{q}^{-36}-2.473 .10^{-5} \mathrm{q}^{-37}$ \\
$\mathrm{BV}_{2}(\mathrm{q})=3.599 .10^{-6} \mathrm{q}^{-36}-2.473 .10^{-5} \mathrm{q}^{-37}$ & $\mathrm{~B}_{2}(\mathrm{q})=-0.04297+0.04297 \mathrm{q}^{-1}$ & $+6.143 .10^{-5} \mathrm{q}^{-38}-4.241 .10^{-5} \mathrm{q}^{-39}$ \\
\hline
\end{tabular}


Table 5 continued

$\begin{array}{ll}\text { DBO ratio } & \text { Residence time ratio } \\ \mathrm{CV}_{1} & \mathrm{CV}_{2}\end{array}$

$\mathrm{MV}_{3}$ steam

$\mathrm{DV}_{1}$ density

$$
\mathrm{B}_{\mathrm{d} 1}(\mathrm{q})=0.02461 \mathrm{q}^{-42}-0.02409 \mathrm{q}^{-43}-
$$$$
0.03526 \mathrm{q}^{-44}+0.03881 \mathrm{q}^{-45}
$$

$\mathrm{DV}_{2}$

inlet

temperature
Outlet digestion temperature $\mathrm{CV}_{3}$

$\mathrm{B}_{3}(\mathrm{q})=0.02461 \mathrm{q}^{-42}-0.02409 \mathrm{q}^{-43}-$ $0.03526 \mathrm{q}^{-44}+0.03881 \mathrm{q}^{-45}$

Table 6 N4SID models for ESSMPC controllers.

\begin{tabular}{|c|c|c|c|c|c|c|c|c|c|}
\hline $\mathrm{A}=$ & $\begin{array}{c}1.0002 \\
0.0004 \\
-0.0012 \\
-0.0028\end{array}$ & $\begin{array}{c}0.0104 \\
0.9777 \\
-0.0254 \\
-0.0076\end{array}$ & $\begin{array}{c}-0.0126 \\
0.0411 \\
0.9893 \\
-0.0610\end{array}$ & $\left.\begin{array}{c}-0.0069 \\
0.1124 \\
0.1074 \\
0.9104\end{array}\right]$ & $\mathrm{B}=$ & $\begin{array}{c}-0.0002 \\
0.0042 \\
0.0022 \\
-0.0059\end{array}$ & $\begin{array}{c}-0.0003 \\
0.0047 \\
0.0027 \\
-0.0053\end{array}$ & $\begin{array}{c}-0.0123 \\
0.0688 \\
0.05 .3 \\
-0.0447\end{array}$ & $\begin{array}{r}0.0002 \\
-0.0286 \\
-0.0106 \\
0.0203\end{array}$ \\
\hline $\mathrm{C}=$ & {$\left[\begin{array}{l}-0.0015 \\
-0.7246 \\
-0.6866 \\
-0.5387\end{array}\right.$} & $\begin{array}{l}0.0015 \\
0.0114 \\
0.2364 \\
-0.195\end{array}$ & $\begin{array}{c}0.0025 \\
-0.2088 \\
0.0235 \\
0.1003\end{array}$ & $\begin{array}{c}0.0006 \\
0.0819 \\
-0.1911 \\
0.0724\end{array}$ & $C_{d}=$ & {$\left[\begin{array}{c}0.0006 \\
0.0016 \\
-0.0035 \\
-0.033\end{array}\right.$} & $\begin{array}{c}-0.0008 \\
0.0011 \\
-0.0041 \\
-0.0033\end{array}$ & $\begin{array}{c}-0.0001 \\
0.0161 \\
-0.0307 \\
0.0207\end{array}$ & $\begin{array}{l}0.0319 \\
0.0394 \\
0.0752 \\
0.0384\end{array}$ \\
\hline
\end{tabular}

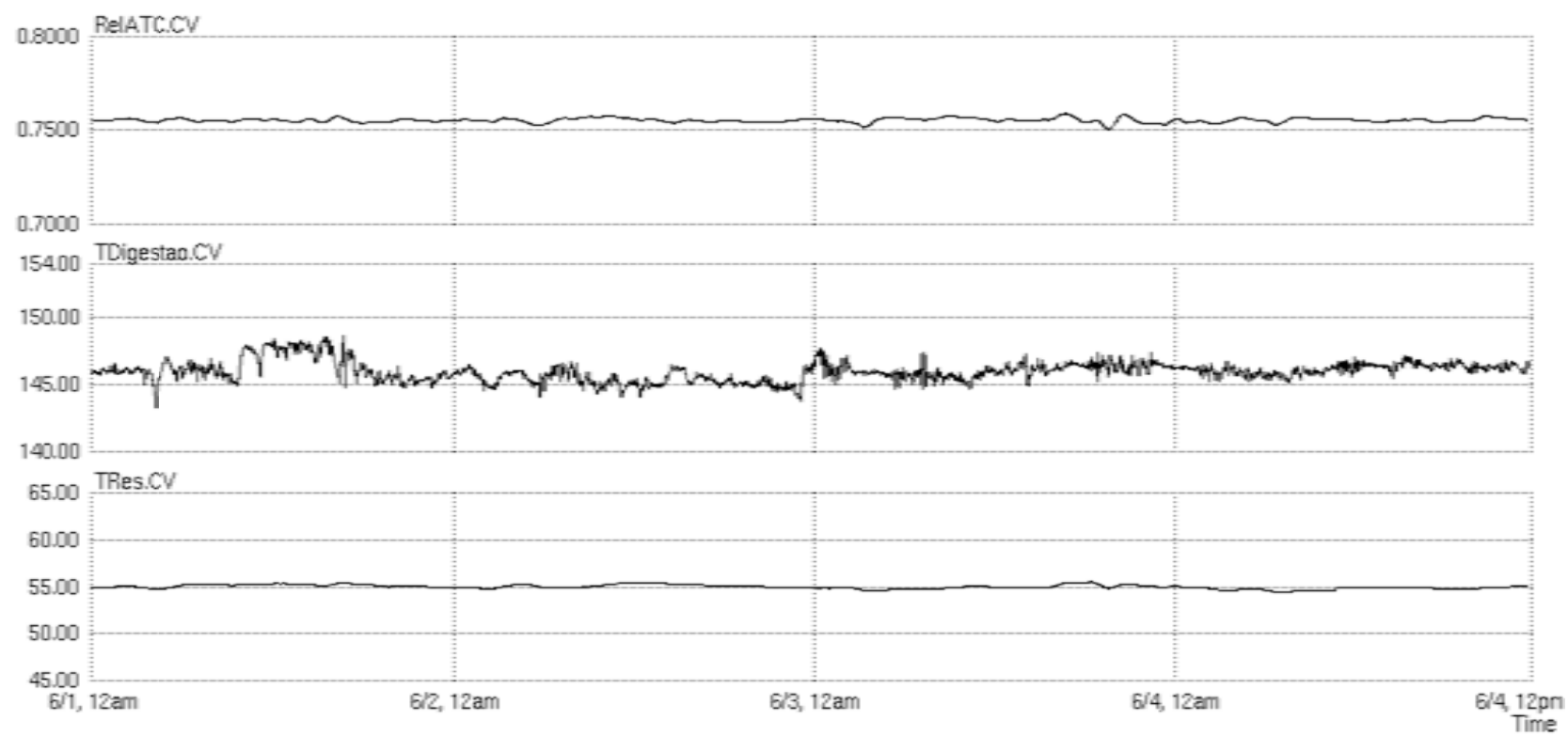

Fig. 4 ESSMPC controlled variables after ESSMPC implementation. 
Table 7 Plant performance indexes with changes in the DBO controller weight.

\begin{tabular}{ccccccccccccc}
\hline \multirow{2}{*}{$\begin{array}{c}\text { Weight } \\
\text { changes }\end{array}$} & \multicolumn{4}{c}{ GPC controller performance } & \multicolumn{3}{c}{ RMPCT controller performance } & \multicolumn{3}{c}{ ESSMPC controller performance } \\
\hline 1 & 0.760 & 1.467 & 1.174 & 0.535 & 0.843 & 2.054 & 1.232 & 0.433 & 0.852 & 1.921 & 1.537 & 0.503 \\
2 & 0.650 & 1.353 & 1.082 & 0.566 & 0.721 & 1.856 & 1.856 & 0.447 & 0.701 & 1.781 & 1.603 & 0.515 \\
3 & 0.630 & 1.258 & 0.755 & 0.650 & 0.649 & 1.621 & 1.296 & 0.493 & 0.647 & 1.685 & 1.180 & 0.601 \\
4 & 0.510 & 1.084 & 0.607 & 0.621 & 0.587 & 1.532 & 1.072 & 0.531 & 0.597 & 1.685 & 1.281 & 0.567 \\
5 & 0.430 & 0.997 & 0.479 & 0.647 & 0.561 & 1.540 & 0.924 & 0.600 & 0.554 & 1.432 & 0.773 & 0.638 \\
10 & 0.340 & 0.836 & 0.334 & 0.649 & 0.554 & 1.439 & 0.604 & 0.700 & 0.551 & 1.395 & 0.502 & 0.752 \\
20 & 0.250 & 0.612 & 0.196 & 0.616 & 0.485 & 1.357 & 0.298 & 0.834 & 0.483 & 1.289 & 0.335 & 0.806 \\
40 & 0.100 & 0.383 & 0.061 & 0.693 & 0.458 & 1.329 & 0.186 & 0.892 & 0.462 & 1.209 & 0.218 & 0.857 \\
\hline
\end{tabular}

10,20 and 40 to analyze the sensitivity of the performance indexes, as shown in Table 7.

Evaluating the results, some observations could be made. Clearly, when the optimization weight increases, the performance for all evaluated algorithms degrades. Nevertheless, the GPC controller performance deteriorates faster than the RMPCT and ESSMPC performances. RMPCT and ESSMPC presented significantly similar performances. The Harris index and $\mathrm{Cp}$ presented similar responses.

\section{Conclusions}

The observations of the results drove important conclusions with respect to the controllers' behavior and to the controller performance indexes. Clearly, the identified model has high impact on the performance index. However, under practical implementation concerns, the identified model is a part of the integral method of the controller. Here, the different identifications were performed with the best practice for the statistical view, and it will be described in another paper.

RMPCT and ESSMPC presented a higher robustness of their algorithms than the GPC algorithm, and because of that, these algorithms presented better behavior than GPC.

Cpk can be used as a good indicator of whether the controller is pushing the process to its constraints. The closer to the constraints it is, i.e., to USL and/or LSL, the more optimized the process is. Thus, the low Cpk can support the comparison between the variable averages and the controller objectives, providing useful information about the degree of process optimization.

Thus, the $\mathrm{Cp}$ and $\mathrm{Cpk}$ indexes should be evaluated together and not separately. This is because the $\mathrm{Cp}$ will show if the process is controllable, and the Cpk will tell whether the process is optimized.

The fact that the Harris index presented similarity with the statistical indexes is an important finding because the CPI assesses the multivariable system and other indices evaluate the system individually, controlled variable by controlled variable. However, a difference between the multivariable index and the univariate index would be expected to some extent.

The robustness presented by the RMPCT algorithm drives it to be less damaged when there are gain mismatches. This robustness is due to the fact that the controller is designed so that it always returns a stable solution.

\section{References}

[1] Garcia, C. E., Prett, D. M., and Morari, M. 1989. "Model Predictive Control: Theory and Practice-a Survey." Automatica 25 (3): 335-348.

[2] Rodrigues, J. A. D., Toledo, E. C. V., and Maciel, F. R. 2002. "A Ttuned Approach of the Predictive-Adaptive GPC Controller Applied to a Fed Batch Bioreactor Using Complete Factorial Design." Computers and Chemical Engineering Journal 26: 1493-1500.

[3] Lu, Z. J., MacArthur, J. W., and Horn. B. C. 1994. Method of multivariable predictive control utilizing range 
control. US Patent 5,351,184.

[4] Di, R. D. 1997. "Model Based Predictive Control: an Extended State Space Approach." In Proceedings of the 36th Conference on Decision and Control, 3210-3217.

[5] Sotomayor, O. A. Z., Park, S. W., and Garcia, C. 2003. "Multivariable Identification of an Activated Sludge Process with Subspace Based Algorithms." Control Engineering Practice 11 (8): 961-969.

[6] Harris, T. J. 1989. "Assessment of closed loop performance." Canadian Journal of Chemical Engineering 67 (4): 856-861.

[7] Desborough, L. D., and Harris, T. J. 1993. "Performance Assessment Measures for Univariate
Feedforward/Feedback Control." Canadian Journal of Chemical Engineering 71: 605-616.

[8] Huang, B., and Shah, S. 1999. Performance Assessment of Control Loops: Theory and Applications, London: Springer-Verlag.

[9] Qin, S., and Yu. J. 2008. "Statistical MIMO Controller Performance Monitoring." Journal of Process Control 18: 277-296.

[10] Lopes, R. L. D., Vieira, L., Oliveira, A., Santos, J., Ribeiro, M., Aldi, J., and Charr, J. 2009. "Advanced Process Control Wide Implementation in an Alumina Digestion Plant." In ADCHEM 2009 Inter. Symp. on Advanced Control of Chemical Processes. p 108. 